\title{
O DIREITO À EDUCAÇÃO NA DEMOCRACIA BRASILEIRA E A QUESTÃO DA SUA EFETIVIDADE
}

\author{
Paula Mangialardo Golin \\ Mestranda em Direito pelo Centro Universitário Eurípides de Marília - UNIVEM e integrante do GEPEDI - \\ Grupo de Estudos e Pesquisas em Pedagogia do Direito do UNIVEM/ MARÍLIA - SP/ BRASIL. \\ e-mail: paulamangialardo@uol.com.br
}

RESUMO: No epicentro da zona impactada pelas novas políticas neoliberais, encontram-se os direitos fundamentais dos homens, principalmente os direitos fundamentais sociais, que são a todo tempo colocados em teste quanto ao seu conteúdo, significado e eficácia. Dentro dos direitos sociais, elegemos o direito à educação como foco principal de nossas reflexões. Têm-se observado uma tendência ao chamado "retrocesso" na tutela dos direitos sociais. O direito à educação é instrumental essencial para a sobrevivência do Estado de Direito, porque ele enseja a própria condição de desenvolvimento da personalidade humana de cada indivíduo, fundamental para que se formem cidadãos. Sinteticamente, esta pesquisa procura concretizar o direito à educação como um direito necessariamente fundamental bem como de conteúdo inseparável do chamado "mínimo existencial".

PALAVRAS-CHAVE: direitos fundamentais. direitos sociais. poder público. Estado. Constituição. direito à educação.

RESUMEN: En el epicenter de la impactada de la zona para el neoliberal nueva política, los derechos básicos de los hombres satisfacen, principalmente los derechos fundamentales sociales, que son todo el tiempo colocó en prueba cuánto a su contenido, significado y eficacia. Dentro de los derechos sociales, elegimos lo derecho a la educación como foco principal de nuestras reflexiones. Han observado una tendencia a lo llamado "retroceso" en tutela de los derechos sociales. Lo derecho a la educación es esencial instrumental para la supervivencia de la regla de la ley, porque intenta el apropiado condicione del desarrollo del est. humano de la personalidad de cada uno individual, básico de modo que los ciudadanos se formen. Sintéticamente, esta investigación busca para materializar lo derecho a la educación como a derecho necesariamente fundamental así como del contenido inseparable de lo llamado "mínimo" existencial.

PALABRAS-LLAVES: derechos fundamentales. los derechos sociales. poder público. Estado. Constitución. derecho a la educación. 


\section{INTRODUÇÃO}

É indiscutível o fato de que nos últimos tempos o planeta passou e ainda está passando por mudanças profundas, chamadas por alguns de evolução e por outros de crise mundial. $\mathrm{O}$ que sabemos é que tais mudanças apresentam um duplo impacto. Por um lado, atingem os modelos de produção na sua base material produtiva e de reprodução, bem como as maneiras de produzir e fazer girar as mercadorias.

Por outro lado, atingem as formas de socialização, a própria cultura, o "estilo de vida das pessoas", assim como as ferramentas de pensamento utilizadas para descrever e explicar a realidade e projetar o futuro.

A verdade é que o mundo se globalizou, não somente nas esferas econômicas, mas inclusive em suas esferas políticas, sociais e culturais.

Torna-se fundamental, assimilar o presente e planejar o futuro, não somente nas dimensões de mercado, empresas transnacionais, Estados-Nação, formação de blocos, mas também nas dimensões locais, individuais, dos "projetos de vida" das pessoas, das realizações de cada um de nós. É necessário pensar a sociedade em que se vive.

E daí, outra questão nos é colocada. Como planejar o futuro e nossas vidas, sem dispormos do conhecimento e informações certos, de idéias formadas, que nos possibilitem compreender o presente?

Diante deste desafio cresce o papel da sociedade e a importância da função social exercida pela educação.

O mundo passa a exigir pessoas e profissionais competentes, permeáveis às mudanças, flexíveis, dotados de iniciativa, liderança, espírito de grupo e criatividade para lidar com quaisquer tipos de problemas propostos, capazes de exercer com maestria a comunicação escrita e oral, estando ainda sempre prontos a aprender sempre mais.

A palavra-chave passa a ser o "aprendizado contínuo", aprendizado para a vida toda, salientando a idéia de que, se as pessoas deixarem de investir no seu próprio aprendizado, estarão destinadas a desatualização, "perdendo o trem da história", arriscando a estabilidade dos seus empregos, minando as novas oportunidades de 
ingresso no mercado de trabalho, perdendo a consciência de suas existências e da realidade que os cerca, entre outras conseqüências.

Assim, "aprender" passa ser uma missão que se estende para muito além dos bancos escolares. O papel da escola, da família, dos grupos sociais, dos educadores e do próprio indivíduo passa a ser redesenhado.

Por isso a relevância do tema ora abordado, que guarda íntima correspondência com a época onde se vive, em que a sociedade se vê diante do fenômeno da globalização e sofre, ao mesmo tempo, todos os seus impactos.

No epicentro da zona impactada pelas novas políticas neoliberais, encontramse os direitos fundamentais dos homens, principalmente os direitos fundamentais sociais, que são, a todo tempo, colocados em teste quanto ao seu conteúdo, significado e eficácia. Sendo a questão da eficácia a que mais nos preocupa e, que também será uma das pautas deste trabalho.

Dentro dos direitos sociais, elegemos o direito à educação como foco principal de nossas reflexões. Buscaremos traçar algumas considerações que, de maneira alguma pretendem esgotar o tema abordado, que em sendo muito complexo, demandaria um fôlego maior que será objeto de outro projeto.

Por ora, comecemos o debate em torno do direito fundamental à educação.

Fato curioso de ser observado é que depois de consolidados e, formadas as primeiras Constituições, alguns direitos conquistados pelos homens nunca foram alvo de grandes discussões, pelo menos por muito tempo. Um exemplo é o direito à privacidade que obriga o Estado e os demais indivíduos a respeitarem a esfera de intimidade de cada pessoa; o direito de ir e vir também pode ser outro exemplo.

Daí, que ao serem contemplados nas Constituições dos Estados os direitos chamados sociais, notadamente o da educação, para que se criassem as maiores celeumas em torno da questão. Debatendo-se, inclusive, sobre o fato dos mesmos tratarem-se ou não, de direitos fundamentais.

Acreditamos que boa parte das discussões são geradas pelo fato destes direitos demandarem a alocação de recursos materiais e humanos por parte do Estado e da sociedade para terem a sua efetividade alcançada.

Seriam direitos onerosos aos cofres públicos em tempos de "vacas magras". 
Para garantir o direito à propriedade, que para alguns se trata de um direito sem custos, quanto à máquina estatal não gasta por mês, entre outras coisas com segurança pública?

Envolvido pelas "teias" da globalização, o Estado-Nação se enfraqueceu, perdendo o controle sobre a sua própria economia e, desta maneira a sua capacidade de garantir e realizar os direitos sociais.

O Estado se privatizou e as maiores conquistas da sociedade deixam de ser direitos para se transformar em mercadorias. Têm-se observado uma tendência ao chamado "retrocesso" na tutela dos direitos sociais. E isto, pode também ser observado na ordem constitucional brasileira, quando, sob o pretexto de enxugamento do orçamento o governo corta gastos com despesas em investimentos sociais para manter o superávit financeiro.

O direito à educação é instrumental essencial para a sobrevivência do Estado de Direito, porque ele enseja a própria condição de desenvolvimento da personalidade humana de cada indivíduo, fundamental para que se formem cidadãos.

Não se pode falar em liberdade para pessoas que nem conhecem o significado que esta palavra carrega.

Sinteticamente, esta pesquisa procura concretizar o direito à educação como um direito necessariamente fundamental bem como de conteúdo inseparável do chamado "mínimo existencial".

\section{OS DIREITOS FUNDAMENTAIS}

Temos como direitos fundamentais os direitos que se referem à condição de pessoa humana, pelo fato em si. Os direitos fundamentais apresentam então as características da irrenunciabilidade, da universalidade, da imprescritibilidade e da inalienabilidade.

São mais facilmente observados por via do historicismo que serve para fornecer uma visão da evolução social que estes direitos sofreram ao longo do tempo.

A doutrina clássica costuma classificar os direitos fundamentais em três gerações. A primeira geração seria a dos direitos individuais e políticos, que são chamados de "direitos de defesa" frente ao Estado, que estabelecem via de regra, os 
limites da ação estatal. A segunda geração refere-se aos direitos sociais, culturais e econômicos, que exigem do Estado uma prestação positiva em face da pessoa humana, visando trazer melhores condições de vida e diminuir as diferenças sociais. $A$ terceira geração abarca os direitos coletivos e difusos, que são direitos despersonalizados, não pertencendo a ninguém em especial e ao mesmo tempo a toda coletividade. Em regra, demonstram preocupações com temas como meio ambiente, direitos dos consumidores, entre outros.

Alexy em sua obra Teoria de los Derechos Fundamentales, apresenta tais direitos divididos basicamente em: direitos de defesa e direitos à prestações.

De acuerdo com la interpretación liberal clásica, los derechos fundamentales 'están destinados, ante todo, a asegurar la esfera de la libertad del individuo frente a intervenciones del poder público; son derechos de defensa del ciudadano frente al Estado`. Los derechos de defensa del ciudadano frente al Estado son derechos a acciones negativas (omisiones) del Estado. Pertenecen al status negativo en sentido amplio. Su contrapartida son los derechos a acciones positivas del Estado, que deben ser incluidas en el status positivo en sentido estricto. Si se presupone un concepto amplio de prestación, todos los derechos a acciones positivas del Estado pueden ser calificados como derechos a prestaciones del Estado en un sentido amplio; dicho brevemente: como derechos a prestaciones en sentido amplio. La cuestión de si y en qué medida a las disposiciones de derechos fundamentales deben adscribirse normas que confieren derechos a prestaciones en sentido amplio es una de las más discutidas en la dogmática actual de los derechos fundamentales. Especialmente se discuten los llamados derechos fundamentales sociales, es decir, por ejemplo, los derechos a la asistencia social, al trabajo, la vivienda y la educación. (Alexy, 1993: 419-420).

Historicamente, os direitos fundamentais de segunda geração surgem como meio de reação aos abusos do modo de produção capitalista no século $X X$, do mesmo modo que o século XIX consolidou os direitos de primeira geração.

Entretanto, Celso Ribeiro salienta que:

(...) esse quadro inicial, contudo, sofreu forte evolução cujas causas dizem respeito à necessidade de enfrentar novas ameaças e novos desafios postos pelos séculos XIX e XX. Os direitos clássicos não desapareceram. Perderam, tão somente, o seu caráter absoluto para ganhar uma dimensão mais relativa, surgida da imperiosidade de compatibilizar o direito com outros princípios constitucionais. (Bastos, 2000: 171-172). 
Porque neste cenário, ouve certa reação contra esse individualismo extremado, por parte de grupos sociais que lutavam para que se reconhecesse nas pessoas, concomitantemente com os direitos de primeira geração, os direitos da chamada segunda geração.

As Constituições passaram a agregar, no seu corpo, constitutivo a noção do Estado de Bem-Estar Social ("Welfare State"). Ou do Estado-Providência, que implica nas prestações positivas do Estado, em face das pessoas, com o fim de proporcionar pelo menos, as mínimas condições de vida e sobrevivência para a população; tais como direito à saúde, à educação, etc.

No Brasil, a Constituição de 1934, foi a primeira a reservar um título específico para a questão da ordem econômica, estando aí incluídos, os direitos sociais. Já na Constituição Cidadã de 1988, aos direitos sociais foi destinado um capítulo próprio, dado especial tratamento aos direitos dos trabalhadores. Ela traz em seu artigo 6 que, "são direitos sociais a educação, a saúde, o trabalho, a moradia, o lazer, a segurança, a previdência social, a proteção à maternidade e à infância, a assistência aos desamparados, na forma desta Constituição."

Os indivíduos passam a cobrar do Estado não mais um comportamento de abstenção, mas sim uma participação ativa na sociedade civil, por meio de prestações positivas por parte dele.

Cumpre ressaltar, já fazendo uma prévia dos itens seguintes que, os direitos fundamentais de segunda geração não são exclusivamente os direitos às prestações positivas do Estado, mas também o são algumas liberdades sociais bem como os direitos fundamentais que regulam o trabalho.

Resumidamente, os direitos de segunda geração surgem pelo fato de que a coletividade passou a perceber que sem igualdade, nenhuma sociedade será realmente livre. Surgindo assim, o conceito, ou melhor, a idéia, do mínimo existencial, este devendo ser garantido pelo poder estatal, a fim de proporcionar as mínimas condições de sobrevivência e dignidade para todos as pessoas. 


\section{O DIREITO À EDUCAÇÃO NO BRASIL}

O direito à educação guarda íntima relação com os princípios fundamentais da República Federativa do Brasil, principalmente porque está diretamente relacionado com o princípio da dignidade humana.

Isto se deve pelo fato de que com a efetividade do direito à educação, tem-se um instrumental poderoso para fomentar o desenvolvimento completo da nação. A educação colabora para uma sociedade livre, mais justa e solidária. Em que cada indivíduo tem a consciência da sua individualidade, juntamente com um forte sentimento de solidariedade social.

Afora o direito à educação guardar forte conexão com o princípio da dignidade humana, como já dito acima, ele ainda estreita vínculo com o direito de liberdade, pois que sem livre determinação não se pode falar em pessoas realmente livres dentro de um Estado de Direito.

Daí, que apesar de se tratar de um direito de segunda geração, é essencial para a defesa e realização de direitos tão imprescindíveis à humanidade como a liberdade e a dignidade (situados nos de primeira geração).

$\mathrm{O}$ direito à educação, mesmo que de diferentes maneiras, ocupou espaço dentro das nossas Cartas pretéritas.

A Constituição do Império do Brasil, de 1824, estabeleceu a gratuidade da instrução primária para todos os cidadãos. Entretanto, numa sociedade em que a maioria da população é constituída por escravos, a restrição de concessão do Direito à Educação, se dará pela definição de cidadania (Oliveira, 1995). É claro que o poder dominante da época já articulava e manipulava os preceitos da constituição de maneira a excluir o direito à educação daqueles que não faziam parte da elite dominante ou do clero.

A Constituição Republicana de 1891, em se tratando de educação, pouco inovou, optando por realizar uma abordagem indireta da educação. Silencia sobre a gratuidade do ensino. Já a obrigatoriedade não passou, seja por causa do Federalismo, seja e, sobretudo pela impregnação do princípio liberal de que a individualidade é uma conquista progressiva do indivíduo que desenvolve progressiva e esforçadamente a sua virtus (Cury, 1996). 
Já a Constituição de 1934, nascida no contexto da Revolução de 30, que levou Getúlio Vargas ao poder, ampliou de maneira significante a presença da educação como preceito constitucional. Sob a inspiração do Movimento dos "Renovadores", a Carta de 34 significou um grande avanço. A Carta de 34 garantiu o direito à educação para todos, sendo responsáveis por ela a família e os poderes públicos, bem como assegurou a gratuidade do ensino primário integral e a sua freqüência obrigatória.

Contudo, estes preceitos nem chegaram a ser aplicados. Porque logo em 1937, Vargas instituiu um regime ditatorial, o Estado Novo, outorgando uma nova Constituição em 1937. Esta significando um retrocesso em comparação à Constituição anterior, especialmente com relação à educação. Afora tivesse preceituado o ensino primário como gratuito e obrigatório, privilegiava o Texto à subsidiariedade do Estado como provedor da educação, somente àqueles deficientes de recursos, numa clara inspiração privatista.

Em 1946, com o fim do Estado Novo e a redemocratização do país, houve a promulgação da Constituição de 1946, que muito se assemelhava às idéias contidas na Carta de 1934. Com relação à educação, a Carta de 46, estabeleceu a obrigatoriedade e gratuidade do ensino primário oficial, conforme estabelecido pela Lei Orgânica do Ensino Primário, também de 1946.

Nos anos de 1948 a 1961, os esforços e debates concentraram-se em função da aprovação de uma Lei de Diretrizes e Bases da Educação Nacional (LDB). A maior polêmica gerada em torno dessa lei foi a questão do repasse de verbas públicas para o ensino privado. Outro aspecto apontado como negativo na lei foi a questão de instituir no seu artigo 30, casos de isenção para a obrigatoriedade do ensino em alguns casos elencados, sendo eles: comprovado estado de pobreza dos pais, insuficiência de escolas, matrículas encerradas, doença ou anomalia grave da criança.

Otaíza Romanelli (Romanelli,1994: 181) aponta que, à exceção do último item, os demais implicam numa redução da disposição dos poderes públicos para que a obrigatoriedade seja cumprida.

Em 1964, temos o golpe militar. E já em 1967, o regime autoritário realizou a reforma da Constituição e "fez" o Congresso aprová-la, sem muita discussão. Contudo, nesta mesma Carta iniciou-se um processo para garantir a obrigatoriedade do ensino 
dos sete aos quatorze anos, sob este aspecto um avanço no tempo de escolaridade compulsória. Ainda, ficavam excluídos aqueles com idade acima dos catorze anos. Esta mesma Constituição incentivava o setor privado com suporte financeiro e técnico, inclusive com oferta de bolsas de estudo.

No ano de 1969, os militares golpistas, pressionados pela radicalização das lutas contra o regime autoritário, decretaram a Emenda Constitucional $\mathrm{n}$ ำ , que de fato representou uma Constituição com características ainda mais ditatoriais que sua antecessora. Todos os preceitos com relação à educação são mantidos, com o avanço de que pela primeira vez reconhece-se a educação como direito de todos e dever do Estado.

Já nos anos 70, a Lei 5.692/71, preservou a fórmula contida na LDB de 1961, confirmando o ensino de $1^{\circ}$ grau como obrigatório para toda a população na faixa etária de sete a quatorze anos.

Com o fim do "milagre econômico" e a retomada das lutas populares no fim dos anos 70 e começo da década de 80 , o processo para a redemocratização do país se acelera, culminando no final dos anos 80 com a promulgação da Constituição de 1988, chamada de a "Constituição Cidadã".

A Constituição de 1988 destinou toda uma seção ao direito à educação, desde o artigo 205 até o artigo 214. Atribuiu a cada um dos entes federativos atribuições de ordem material, onde estipulou que cada um deles deve contribuir, anualmente, com um percentual mínimo estabelecido em lei, proveniente das suas receitas.

Sendo fixado o percentual da União em dezoito por cento e, o dos Estados, Distrito Federal e Municípios fixados em vinte e cinco por cento.

Tendo o Brasil adotado a forma de Estado federativa, o constituinte além de definir atribuições de ordem material, cuidou de regular a competência legislativa. À União compete legislar, de maneira privativa, sobre as diretrizes e bases da educação em todo o Brasil, conforme o artigo 22 inciso XXIV da Constituição. Poderá ainda, legislar de maneira concorrente com os Estados e o Distrito Federal, sobre o que consta do artigo 24 inciso IX, que trata da educação, cultura, ensino e desporto. Aqui neste artigo, o seu parágrafo primeiro restringiu a sua competência à edição de normas gerais. Em havendo necessidade, os Estados poderão legislar sobre as matérias que ainda não tenham sido alvo de leis federais, com eficácia até que a União disponha 
sobre os assuntos. O constituinte tratou de enumerar as obrigações do Estado com relação à educação no artigo 208 da nossa Carta Magna.

Nota-se que o constituinte originário, mais do que simplesmente enumerar, tratou de afirmar que o ensino obrigatório, mais do que uma norma programática, tratase de um direito público subjetivo. Desta maneira, ele quis tornar exigível a sua total efetividade. Não deixando dúvidas de que para a Carta de 1988, o direito à educação, pelo menos a fundamental, é parte da condição de dignidade da pessoa humana e, que integra o que se chama de mínimo existencial.

No ano de 1990, tivemos editada no dia 13 de julho a Lei $n^{\circ}$ 8.069, que estabeleceu o Estatuto da Criança e do Adolescente e outras providências. Tal lei buscou dar real efetividade ao que já fora tratado na Constituição, pois que o texto constitucional é visto muitas vezes como mera declaração de direitos, consignando que os direitos expressos no estatuto e outros já garantidos por lei, têm assegurados de forma expressa, a sua exigência junto ao poder judiciário.

Assim, o legislador infraconstitucional optou por dar efetividade ao direito à educação por caminho diverso do legislador constituinte, ao prever a imediata exigibilidade destes direitos prestacionais (em não observados) perante o poder judiciário.

A Lei de Diretrizes e Bases da Educação Nacional, Lei ํㅜ 9.394/96, em seu artigo 5ำ, também fez questão de ressaltar a garantia de sindicabilidade junto ao poder judiciário como meio de dar efetividade aos direitos nela consagrados.

Também o artigo 227, caput da Constituição, tratou de assegurar às crianças e aos adolescentes vários direitos, entre eles, o da educação, em que eles terão absoluta prioridade com relação ao seu gozo.

É de se notar que o legislador constituinte pretendeu eliminar atos de discricionariedade do administrador público com relação ao direito à educação das crianças e dos adolescentes, realizando a priori, a ponderação entre os princípios que julgou serem os mais relevantes para a sociedade.

Todavia, uma questão não pode deixar de ser aqui comentada, trata-se do problema da colisão de princípios. 
Os princípios elencados na Constituição, sucessivamente entram em colisão entre si, o que advém da falta de limites exatos do conteúdo e alcance de cada um deles. Nos casos em que se verificam os conflitos, a técnica de ponderação de Robert Alexy poderá ser instrumental eficiente para a solução destes embates.

Esta ponderação, contudo, não deverá ser realizada em uma atmosfera de puro subjetivismo, pois isto em vez de apontar soluções, seria mero arbítrio. Conforme Alexy (Alexy, 1993: 92-94), deve ser ela orientada por critérios racionais que acabarão por determinar uma relação de precedência condicionada, apontando para o princípio que, naquela situação, possuí o maior valor, depois de verificadas as condições específicas que integram tal ponderação.

Por meio desta ponderação, se construirá uma lei de colisão, por via da qual as condições que levam à preferência de um princípio sobre o outro formam o pressuposto fático de uma regra que justifica a conseqüência jurídica do princípio precedente, onde temos que, quanto mais desprestigiado for um princípio, maior deverá ser a importância do outro princípio que for satisfeito. Resumidamente, esta seria a técnica de ponderação de Alexy, que serve para solucionar todas as situações de colisão entre princípios, principalmente daqueles que tratam de direitos fundamentais.

\section{O DIREITO À EDUCAÇÃO E O MÍNIMO EXISTENCIAL}

Denominado também de núcleo comum dos direitos fundamentais, o mínimo existencial define o conteúdo mínimo e inderrogável destes direitos. Tal conteúdo mínimo dos direitos fundamentais, hoje amplamente aceito e generalizado, é fruto de sua recepção nos tratados internacionais, nas cartas políticas e de sua propagação na esfera legislativa infraconstitucional.

O conteúdo mínimo agrega a essência dos direitos fundamentais, e por isso mesmo é proibido ao Estado a tomada de medidas, sejam elas de natureza legislativas ou materiais, omissivas ou comissivas, com o fim de impedir a sua concreção.

Entretanto, apesar da sua existência e importância serem inquestionáveis, o mínimo existencial, que necessita de condições materiais para ser efetivado, encontra problemas em ser realizado porque os seus limites não são exatos. 
Nos países de terceiro mundo, como o Brasil, pode-se afirmar que o mínimo existencial é ignorado pelas autoridades estatais. Grande parte da população vive em condições sub-humanas, sem qualquer tipo de auxílio do poder público.

Tratando-se do direito à educação fundamental, desnecessário afirmar que estamos diante de uma parcela integrante do mínimo existencial, não somente porque a legislação constitucional assim balizou, como porque trata-se a educação de prérequisito para a concreção de outros direitos fundamentais dos homens, como a liberdade.

No Brasil, desde a primeira Carta já havia menção ao direito à educação, além disso, a Constituição de 1988 tratou de elevar tal direito à condição de direito público subjetivo, o que em muito colabora para que tal princípio saia do campo das abstrações para se tornar concreto, afastando quase todas as possibilidades do Estado de negar a sua realização.

Para a efetivação do direito à educação, não só ela deve ser ofertada pelos poderes constituídos, como também são necessárias ações paralelas no sentido de permitir que as pessoas tenham condições de chegar até a escola, de freqüentar as aulas, de manter-se em pé durante as aulas. A miséria do povo brasileiro é tão gritante que na falta destas ações o direito em si, mesmo que regularmente ofertado, não atenderia às suas finalidades. Pensando nisso, o legislador tratou de elencar uma série de medidas que venham possibilitar o gozo desse direito, mesmo para os mais pobres, através dos programas de merenda escolar, transporte, entrega de material didático, entre outros.

Assim, que traçados alguns balizamentos acerca do mínimo existencial, é sempre relevante salientar que destoa dos princípios por ele representados quaisquer medidas dos poderes públicos, que tenham por objetivo eliminar direitos, garantias e liberdades que já tidos como parte integrante deste mínimo.

Estamos diante da chamada "proibição de retrocesso social", parecendo óbvio que ao longo do tempo, a tendência deve ser a de sempre haver melhorias na vida dos indivíduos tal qual a sociedade se desenvolve. Mas o contrário ocorre, na medida em que os recursos vão se tornando cada vez mais escassos diante do aumento das necessidades. E é por isso que, em relação ao direito à educação, se faz necessário 
conhecer os mecanismos que podem garantir a efetividade deste direito imprescindível para a realização completa de toda pessoa.

\section{A EFETIVIDADE DO DIREITO À EDUCAÇÃO}

A Constituição Federal de 1988 dispõe em seu artigo 5ํㅡ, parágrafo primeiro, que "as normas definidoras dos direitos e garantias fundamentais têm aplicação imediata". Não resta dúvida que o poder constituinte originário decidiu outorgar às normas de direitos fundamentais uma normatividade extra, no sentido de caracterizar que a efetivação das mesmas não se encontra mais a critério do legislador infraconstitucional.

Mesmo havendo na doutrina posição divergente, entendemos que a norma expressa no artigo 5º, parágrafo primeiro da Constituição, afora ser aplicável a todos os direitos fundamentais, inclusive os de ordem social como o da educação, possuí a característica de ser uma norma-princípio, revelando-se como um mandado de otimização que ordena ao poder público que atribua aos mencionados direitos, toda a eficácia e efetividade possíveis.

Comentávamos no final do capítulo anterior sobre o princípio denominado "proibição de retrocesso social", que apesar de ainda não estar totalmente incorporado à nossa cultura política, tem merecido grande destaque dentro da doutrina que defende o Estado Democrático de Direito, eleito pela nossa Constituição.

Referido princípio, ainda que não tenha a imperatividade de desconsiderar toda e qualquer margem de discricionariedade de que dispõe o legislador em uma democracia, tenta evitar que o poder legislativo possa destituir sem razão a própria margem de concretização que ele mesmo havia conferido às normas da Constituição. $E$ esse cuidado ocorre principalmente quando tais normas constitucionais dependerem em maior grau, de leis infraconstitucionais para terem os direitos e as garantias efetivados, sendo cumpridos pelo poder público e por particulares, quando for o caso.

Assim, a via judicial seria o caminho correto para os casos em que o legislador desordenadamente revogar, no todo ou em parte, normas infraconstitucionais que efetivaram direitos e garantias consagrados pelo constituinte originário. Mesmo que não haja mudanças na própria Constituição, o que só pode ser feito mediante as hipóteses 
e limites nela expressos, ainda assim grandes barreiras estariam sendo erguidas contra os fundamentos da nossa Carta Magna. Em que por via do judiciário poderia se pleitear a inconstitucionalidade de tais normas.

Para o ilustre autor J. J. Canotilho (Canotilho, 1991: 321), o princípio da proibição de retrocesso social pode assim ser caracterizado:

(...) o núcleo essencial dos direitos sociais já realizado e efetivado através de medidas legislativas deve considerar-se constitucionalmente garantido, sendo inconstitucionais quaisquer medidas estatais que, sem a criação de outros esquemas alternativos ou compensatórios, se traduzam na prática numa 'anulação', 'revogação` ou 'aniquilação' pura e simples desse núcleo essencial.

Acontece, todavia, que o princípio da proibição de retrocesso social, não é acolhido por toda a doutrina, que utiliza o argumento de não se poder engessar o legislador, por conta de uma interpretação dos direitos elencados na Constituição.

Mas na verdade, ocorre que por trás deste argumento contra o mencionado princípio, esconde-se o fato de que o direito à educação bem como os demais direitos sociais prestacionais, dependem da alocação de recursos materiais e humanos para terem a sua efetividade consagrada. Estando a realização destes direitos condicionados à existência de uma reserva disponível de recursos.

Várias questões poderiam aí ser suscitadas; a de que em se tratando de recursos públicos, apenas o legislador democraticamente legitimado possuiria competência para tratar da distribuição destes recursos; a de que o poder judiciário não poderia, em tese, decidir sobre as políticas orçamentárias, sob pena de estar ferindo o princípio da separação dos poderes, entre várias.

Em se tratando do direito à educação, parece-nos que a edição da Lei nํ 9.424, de 24 de Dezembro de 1996 e do Decreto Federal no 2.264, de Junho de 1997, introduziram mudanças no que diz respeito ao ensino fundamental, determinando legalmente como a partilha de recursos deverá ser feita e em que medida, conforme o disposto no artigo 70 da Lei no 9.394/96. Não havendo espaço para muita discricionariedade por parte do legislador infraconstitucional. 
Com relação à atuação do Judiciário, não nos parece que haverá interferência no âmbito dos outros poderes, mas apenas ele tratará de velar para que haja adequação com a norma jurídica, papel que lhe cabe dentro do regime democrático.

Em havendo problemas com a colisão de princípios (direito à educação e demais direitos), a solução será analisar, cada caso em concreto, como já mencionado realizando a ponderação dos valores em jogo, fazendo prevalecer os princípios que forem mais relevantes para aquele caso específico.

A busca pela efetividade de todos os direitos conquistados deve ser permanente e sempre realizada da maior e mais completa forma possível, além da obrigação dos poderes públicos em velar pelos direitos e garantias fundamentais, a sociedade deve assumir o seu papel porque isso é dever do cidadão que vive em uma democracia.

\section{CONCLUSÃO}

É inegável que a conquista e o reconhecimento dos direitos sociais constituí uma grande vitória na luta por uma vida melhor para todo ser humano. Entretanto, tais conquistas enfrentam grandes desafios impostos pela globalização e pelos modelos econômicos neoliberais. Tendo como efeito o entrave à realização de alguns direitos fundamentais, por exemplo, no que diz respeito à escassez de recursos disponíveis para a realização destes direitos.

O direito à educação é direito fundamental e imanente à condição de dignidade dos seres humanos, ele é requisito para a concreção da cidadania.

Dadas as três gerações de direitos fundamentais, que coexistem harmonicamente, o direito à educação é incluído no rol dos direitos sociais que se enquadram no campo dos da segunda geração. Apesar disto, ele é peça essencial à realização dos direitos da primeira geração.

Essencial que se estabeleça um mínimo existencial, sem o qual se torna impossível à sobrevivência da pessoa humana e a efetivação do princípio da dignidade da pessoa humana.

Além da perspectiva historicista, a nossa Carta Magna de 1988, consagrou e tornou incontroversa a imediata exigibilidade do direito à educação junto aos poderes 
públicos, erigindo-se à condição de direito subjetivo público. Passível de ser pleiteada a sua efetividade por via do poder judiciário.

A atividade jurisdicional que imponha a obediência da Constituição Federal e da legislação infraconstitucional, operando a concretização daquele e de outros direitos essenciais à dignidade humana, de maneira alguma ferem o princípio da separação dos poderes. Pelo contrário, é instrumento legítimo consagrado pela própria democracia, indispensável à guarda dos direitos e garantias fundamentais.

Apenas nos casos extremos de falta de recursos, o que deve ser provado pelo poder público que alegar tal inexistência, será possível a alocação de outros recursos para se determinar o contingenciamento de verbas orçamentárias para a satisfação dos direitos prestacionais, como é o caso do direito à educação.

$\mathrm{Na}$ ocorrência da colisão de direitos fundamentais, em que haja a escassez de recursos para atendimento dos mesmos, deve-se diante do caso em concreto ser realizado um juízo de ponderação que melhor equacione a justiça social e implemente a efetivação dos direitos.

\section{REFERÊNCIAS BIBLIOGRÁFICAS}

ALEXY, Robert. Teoria de los Derechos Fundamentales. Trad. Ernesto garzón Valdés. Madrid: Centro de Estudios Constitucionales, 1993.

BASTOS, Celso Ribeiro. Curso de Direito Constitucional. 21르 ed. São Paulo: Saraiva, 2000.

CANOTILHO, José Joaquim Gomes. Direito Constitucional e Teoria da Constituição. $2^{\underline{a}}$ ed. Coimbra: Editora Almedina, 1998.

CURY, Carlos R. J. A educação e a primeira Constituinte republicana. In Fávero, Osmar (org.). A educação nas Constituintes brasileiras (1823-1988). Campinas-SP: Autores Associados, 1996.

OLIVEIRA, Romualdo P. Educação e cidadania: o direito à educação na Constituição de 1988 da República Federativa do Brasil. São Paulo, 1995. Tese de Doutoramento. FEUSP.

ROMANELLI, Otaíza de Oliveira. História da Educação no Brasil. 16ª ed. Petrópolis-RJ: Vozes, 1994.

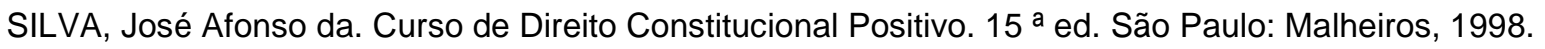

